\title{
Sobre as responsabilidades e liberdades de se discutir o suicídio
}

\author{
Fernanda Ferreira \\ Gabriel Pinezi \\ Willian André
}

\begin{abstract}
o suicídio continua a ser um dos tabus remanescentes da nossa era. Ato que rejeita completamente até mesmo o mundo que deve sancioná lo, ele é uma "negação da promessa liberal sobre a qual as democracias modernas se sustentam" (Lisa Lieber man). Mas é também um tabu muito curioso. Está claro que não se trata do caso de não podermos comentá-lo ou abordá-lo. O suicídio é estudado, relatado, analisado, e regularmente discutido em diversos contextos, tanto dentro quanto fora dos regimes disciplinares dos múltiplos discursos, especialmente na psicologia, sociologia, estudos sociais, medicina, ética, psiquiatria, etnografia, epidemiologia, historiografia, e na própria suicidologia. Trata se também de um ato ou evento central em inúmeros romances, pinturas, contos, poemas, peças, filmes, canções e outros artefatos cultu rais. O forte tabu da morte voluntária, todavia, é herdado das restrições ou limitações sobre como o tópico pode ser abordado. Substituindo a hegemonia dos discursos legal e teológico sobre o suicídio enquanto crime ou pecado, dominante desde os tempos de Santo Agostinho até o fim do século 18, pelo menos, assim como a médi calização do ato simplesmente como atributo da loucura - consequência de se estar non compos mentis ou sofrendo de "insanidade temporária" (motivo que se desen volveu e se tornou dominante no fim do século 18 e ao longo do 19) -, a compreen são moderna do suicídio é construída, mesmo (ou especialmente) na medicina e na psiquiatria, em termos de interdição, como estratégia e prática de prevenção. Qual quer coisa que resista ou ameace a interdição do ato tende a ser instantaneamente negada e proibida. (...) há uma inquietação social penetrante a respeito das represen tações do autoaniquilamento que não o denunciam e interdizem explicitamente: a única forma de discurso inteiramente legítimo sobre o suicídio é o discurso da pre venção (Andrew Bennett, Suicide Century: Literature and Suicide from James Joyce to David Foster Wallace).
\end{abstract}

As atividades de preparação deste dossiê temático sobre literatura e suicídio foram iniciadas por volta de agosto de 2018. Estávamos às vésperas da quarta edição da cam panha nacional "Setembro Ama relo" quando divulgamos a chama da para publicação. Deste momento até as primeiras reações negativas à nossa iniciativa foi um tempo bem curto. Ainda temos bem guardados os muitos e mails que trocamos quando, nas redes sociais, começa ram a surgir as acusações: de que estávâmos "romantizando, o suicí dio"; de que estávamos sugerindo que a escrita é "porta de entrada para o autoaniquilamento"; de que 
nossa chamada louvava o "gênio suicida" e a "beleza da morte auto infligida".

Essas interpretações equivocadas são bem explicadas pela longa cita ção de Andrew Bennett que esco lhemos para a epígrafe desta apre sentāção. Apesar da necessidade premente de se discutir o suicídio, num momento em que os índices de mortes voluntárias atingem os nú meros mais alarmantes, os discursos sobre $o$ ato ainda são construídos sob a égide do preconceito. Con forme esclarece Bennett, o autoani quilamento sempre se configurou como tabu, e sua "versão" mais atual - reinante principalmente desde as últimas décadas do século XX - veste a máscara da prevenção: fala se muito a respeito do tema, mas só são legitimados os discursos que se mantêm no/conforto do dis tanciamento, reduzindo o suicídio a um cancro maligno que precisa ser combatido e eliminado. É por isso que a maioria das pessoas - algu mas delas, realmente bem intencio nadas - não consegue conceber ou tra abordagem sobre o assunto que não seja a preventiva, talvez por medo de encarar o problema dire tamente, como já apontava A. Alva rez no início dos anos ' 1970.

Ao propor úm dossiê temático sobre literatura e suicídio, estamos definitivamente preocupados com o problema que o tema encerra em suas mais diversas dimensões, mas ao mesmo tempo estamos escolhen do uma abordagem que não é a preventiva - e que, nem por isso, precisa ser "menos legítima". A lite ratura, afinal, sempre se prestou ao trato de assuntos muito espinhosos e delicados. Kafka já nos ensinava, há bastante tempo, que "os livros de que precisamos são aqueles que agem sobre nós como uma desgra ça, que nos fazem sofrer como a morte de quem amamos mais do que a nós mesmos, que nos fazem sentir como se à beira do suicídio". E este tema, o suicídio, a literatura o aborda, desde a Antiguidade até o presente, sob diversas perspectivas e com muita sensibilidade - o que é possível constatar pela riqueza de conteúdos que compõem este volu me de Criação \& Crítica.

Contradizendo as críticas mal fundamentadas, mais de quarenta manuscritos foram submetidos ao dossiê, revelando a necessidade de se dar espaço a estudos sérios sobre o tema. Os trabalhos que recebemos passaram por processos de avalia ção em que 'se fez fundamental o crivo de profissionais com conhe cimentos específicos nas áreas abordadas. Como resultado desses processos, reunimos aqui um total de nove artigos, uma tradução e um exercício de estilo, que, no conjun to, vêm colaborar para a solidifica ção dos estudos brasileiros sobre o suicídio na literatura. Entre várias alternativas possíveis, optamos por organizar o material a partir de uma perspectiva historiográfica, levando em conta os autores e obras trabalhados em cada texto.

Dessa forma, abre o dossiê Pier Della Vigna x Catão de Útica: dois suicidas da Divina Comédia dantesca, artigo em que Maria Célia Mar tirani Bernardi Fantin investiga o aparentemente contraditório trata 
mento conferido por Dante aos dois suicidas que dão nome ao trabalho. Enquanto Piẹr Della Vigna é manti do na floresta dos violentos contra si mesmos, no Sétimo Círculo do Inferno (Canto XIII), Catão de Útica recebe melhor sorte, permanecendo como guardião do Purgatório (Can to I). Conforme a leitura de Fantin, a quase "absolvição" de Catão por Dante se deve ao gesto de nobreza envolvido no suicídio do republica no uticense.

Do final da Idade Média ao ro mantismo do século XIX, passamos ao artigo $\mathrm{O}$ suicídio como aprendi zagem: uma leitura do poema "Rol la" de Musset feita por Álvares de Azevedo, de Natália Gonçalves de Souza Santos. Abordando o ensaio "Alfredo de Musset: Jacques Rolla", em que Azevedo apresenta uma tradução parcial do poema cujo protagonista homônimo é um suici da, a autora do artigo investe na percepção alvaresiana de que a morte voluntária acaba por se con figurar, para Rolla, como etapa de formação e amadurecimento, con ferindo lhe uma percepção mais aguda da existência.

Se os dois primeiros artigos par tem de uma abordagem mais base ada na metodologia historiográfica, em Quando um heterônimo se suicida: tanatografia e alteridade na Educação do estoico, do Barão de Teive, Ana Clara Magalhães de Me deiros e Augusto Rodrigues da Silva Junior apostam na construção de um texto bastante poético que ana lisa o único manuscrito deixado pe lo pouco conhecido (e suicida) he terônimo pessoano Barão de Teive.
Partindo da perspectiva dialógica bakhtiniana, os autores refletem sobre alteridade e escrita da morte em Educação do estoico, empreen dendo ainda um diálogo necessário com a filosofia do estoicismo.

Do modernismo português ao Ja pão, chegamos ao primeiro artigo do dossiê sobre um autor que efeti vamente tirou a própria vida, para além de ter abordado o tema em seus escritos. Em Suicídio, desejo e gozo na escrita literária: uma análi se psicanalítica do "Patriotismo" de Yukio Mishima, Rafael Salmazi Sachs e Renan Kenji Sales Hayashi propõem uma análise do conto " $\mathrm{Pa}$ triotismo", de Mishima, que viria a cometer o sepukku. Além de propor o estudo a partir da perspectiva da Análise do Discurso, os autores dia logam principalmente com a psica nálise lacaniana, procurando des lindar, a partir das ações ritualísti cas e do pacto suicida narrados no conto, relações entre autoaniquila mento e sublimação.

$\mathrm{Na}$ sequência, entra em cena o primeiro artigo do dossiê que trata de autoras. Em Sylvia Plath, Cláudia Roquette-Pinto e os limites da escri ta: uma poética do autoaniquila mento, Aline Leal Barbosa propõe uma associação anacrônica entre a poética das duas escritoras: a pri meira, uma "suicida literária" que veio a ser reconhecida como uma das principais poetas do século XX; a segunda, autora contemporânea em cuja construção poética a pri meira se faz presente. A' leitura bus ca encontrar pontos de semelhança e de dissonância entre as obras de las, observando, em questões que 
passam por materialidade do corpo, feminismo e linguagem, como a de sestabilização do real por meio da última fomenta o aniquilamento em variadas formas.

Ainda sobre escritoras suicidas: Lara Luiza Oliveira Amaral, em "Para os não nascidos": a peça suicídio de Sarah Kane, reestabelece um tom poético no desenvolvimento do dossiê em sua análise de Psycho sis 4.48 , a última peça escrita por Sarah Kane pouco antes de enfor car se com os próprios cadarços em uma clínica de observação para sui cidas. Apostando na interpretação do texto de Kane enquanto "bilhete suicida" metafórico, a autora anali sa tanto os movimentos estéticos da peça quanto os conflitos de uma subjetividade cindida em um texto dramático que problematiza os próprios limites do drama e a con dição da individuálidade maníaco depressiva.

No artigo seguinte, temos um es tudo sobre David Foster Wallace, autor que se aproxima de Kane não só pela pertença de ambos às litera turas anglófonas, mas também pela proximidade no modus operandi de seus destinos trágicos: nove anos depois do suicídio da dramaturga britânica, o norte americano Wal lace também se mataria enforçado. É partindo da narrativa construída acerca da morte do autor que Mar cos Namba Beccari, no artigo Você acaba se tornando vocề mesmo? $\mathrm{O}$ personagem David Foster Wallace, problematiza - em diálogo com o filme The End of the Tour, de 2015, dirigido por James Ponsoldt e base ado no relato biográfico Although of course you end up becoming yourself (2010), do jornalista David Lipsky - o quanto o suicídio de Wallace influencia, de forma mui tas vezes determinista, toda a traje tória artística do escritor - movi mento que aponta para a criação de um "Wallace personagem".

Prosseguindo com os autores contemporâneos, Ricardo Augusto de Lima, em Sergio Blanco (1971 2015): o suicídio como ato poético, observa a performance por trás da morte de um personagem homôni mo do dramaturgo franco uruguaio Sergio Blanco na peça La ira de Narciso. Partindo das discussões de Maurice Blanchot em especial, o autor do artigo analisa a experiên cia literária da autoria como espaço de morte, e também como Blanco consegue encenar esse aniquila mento autoral em sua peça, uma mórte simbólica e performática, uma morte voluntária que passa, neste caso, pela discussão sobre a morte do autor e sobre as proble máticas em torno da questão da au toria, da leitura e da linguagem.

Fechando o conjunto dos artigos, Rodolfo Rorato Londero, em "Tarde demais para morrer jovem": de pressão e suicídio na literatura bra sileira contemporânea, propõe es tudo sobre textos de Daniel Galera, Julia Wähmann, e Frederico Barbo sa. Ao abordá los, observa como eles tratam da depressão em seus escritos, explorando a tensão entre a doença e o suicídio fora da nor malização do discurso positivo da prevenção. Em sua conclusão, o au tor observa que o discurso da au toajuda e das campanhas de pre 
venção "fazem falar o que a socie dade gostaria de ouvir", e, situando a literatura como uma via de abor dagem que consegue escapar dessa perspectiva, ecoa justamente o tom com que iniciamos este texto de apresentação.

A tradução do textó de Qui Phiet Tran, A questão do suicídio em $O$ som e a fúria, realizada por Willian André, encerra bem a perspectiva dos artigos que compõem o dossiê: o vietnamita defende, ao tratar do romance de Faulkner e de seu per sonagem suicida, Quentin, a neces sidade de analisar o suicídio de ma neira mais complexa e profundo do que o clichê imposto. Para alcançar essa leitura mais plurissignificativa, o crítico observa a trajetória do per sonagem considerando o caráter individual do suicídio, na tentativa de não resvalar nas armadilhas que o tabu oferece.

Por fim, acrescentando um tom artístico ao fechamento do dossiê, temos o exercíció de estilo Anda vivo, não morreu: ensaio sobre Tor quato Neto, de Rodrigo Lobo Da masceno. Se o primeiro artigo deste volume apresentava, em certo ponto, uma reflexão sobre a figura de Catão, que preferiu a morte volün tária ao jugo do Império Romano, neste último texto encontramos uma atualização dessa mesma ques tão que, para além de ética, é políti ca. Ecoando, em certa medida, as palavras de Artaud sobre o "suici dado pela sociedade" Van Gogh, Damasceno reflete sobre a figura icônica do poeta e músico brasileiro Torquato Neto, associando seu sui cídio à conjuntura política do regi me ditatorial brasileiro, e expan dindo a questão não só para demais ditaduras da América Latina, mas também, em um movimento extre mamente necessário e atual, para a configuração política mais recente do Brasil.

Em visada geral, esses onze textos que compõem o dossiê "Morrer pe las próprias mãos: literatura e sui cídio" (até onde nos consta, o pri meiro dossiê publicado por um periódico brasileiro sobre as relações entre literatura e suicídio), com seus diversos objetos de pesquisa e perspectivas de abordagem, com põem I um mosaico suicidológico que possibilita não apenás um aprofundamento de nossos conhe cimentos sobre o autoaniquilamen to na matéria literária, mas também um olhar mais sensível e plurissig nificativo para o ato limítrofe de se tirar a própria vida enquanto irre cusável patrimônio humano. Regis tramos aqui nossos sinceros agrade cimentos a todos os autores e avali adiores que colaboraram com o dos siê pelo apoio sério com que nos presentearam. Desejamos uma boa leitura e uma vida longa a todos que se interessam pelo assunto. 